modic form. It must be remembered, too, that there are many diverse causes of chorea. Some cases of Sydenham's chorea may be of infectious origin, but they are not by any means all of infectious origin. One could not for a moment believe that cases of chorea induced by fright, as many are, could be due to infection, nor can the numerous cases due to an overstrain of study or school be of infectious origin. 'There are also met with several types of Sydenham's chorea in which the symptoms vary to a marked extent, so it seems important that in the study of chorea and of choreiform affections one should discriminate more fully between the different forms of the disease which are met with.

DR. J. A. Honars, Richmond, Va., emphasized the causal relation of rheumatism and chorea. Having been impressed as a student with the theory that this disease is almost inseparably connected with rheumatism as a causal factor, Dr. Hodges expected to find it in a great majority of his cases; however, during an experience of ten years he has not seen a single case of chorea associated with rheumatism. Likewise, he has only seen two cases suffering with heart lesions and only two that were supposedly due to toxins, though he is not absolutely positive about these, as neither case died and he did not have the opportunity of extending his investigations into the definite cause of the disease. Many neurasthenic conditions, he believes, may be the cause of this disease. Dr. Hodges referred to the calmative effect of iron on muscular tissues. In a number of cases in which neither small nor large doses of arsenic would control the spasmodic manifestations, iron caused marked improvement.

Dr. ALRERT E. STERNe, Indianapolis, stated that a great many cases of tic of the convulsive sort have absolutely failed to be benefited by any method that he has ever employed. The older the patient is the poorer the prognosis becomes. The prognosis is rery much better in children and decreases as the patients advance in age. There must be a fundamental weakness for the manifestations exhibited in chorea, because the same elements which produce chorea in these individuals have absolutely no effect on persons not predisposed to the condition through fundamental nervous weakness. He believes that there is a very distinct relationship, in a large percentage of cases, between Sydenham's chorea and acute arthritis. It is perfectly natural in a predisposed case that there be a joint manifestation which is frequently overlooked. He has seen many cases beginning in chorea which have developed heart disease only, or arth. ritis and endocarditis, successively. Chorea may be either the first or the last in the trinity of diseases. In the case of a child which had injured itself by eutting with a piece of tin, the wound would not heal, but remained open, and the child successively developed arthritis, endocarditis and chorea; all disappeared under treatment, but again she developed arthritis, endocarditis and chorea, and died. Dr. Sterne could not recall a single case where tuberculosis was associated with chorea.

DR. W. C. Jones, Walnut Springs, Texas, declared that in his state there is a great deal of chorea and very little rheumatism, and still less cardiac trouble.

Dr. WM. G. SpILler, Philadelphia, briefly referred to a case which at first was under the charge of Dr. Mills and which then passed under his care. The patient was operated on, the spinal accessory nerve being resected and two inches removed. The man continued to jerk his head, and a Keen nperation was performed and the nerve supply of the museles of the back of the neck and finally the nerve supply of the corresponding museles on the other side of the neck cut also. The patient left the hospital very much improved. Dr. Spiller recently saw a patient who had convulsive movements of the muscles of the neck and of the face, who was discharged from the hospital cured after resection on each side of the spinal accessory nerve, but he stated that he failed to see how this could have cured the movements unless by suggestion. Dr. Spiller regards senile chorea as a more serious condition than Sydenham's chorea and thinks it may be difficult at times to diagnose the senile forms from
Huntingdon's chorea. He thinks that at times there is a relation between Sydenham's chorea and rheumatism but that it is often much exaggerated.

Dr. Hugh T. Patrick, Chicago, confirmed Dr. Spiller's statement that implication of the muscles of the eye is rery unusual in chorea. Aside from oceasional choreiform rolling of the eyeballs, he had never seen marked implication of the eye muscles until recently. A few months ago he saw a boy of 5 with very severe chorea, confining him to bed, and the eyeballs were in constant, irregular, jerky motion. He had never seen anything approaching it except in a few cases of very grave organic disease, and when he first looked at the boy he supposed he had to deal with some serious lesion. The case, however, proved to be a typical one of Sydenham's chorea, and the child gradually recovered. In the treatment, he favors very large doses of arsenic. His opinion is that large doses will produce effect when smaller ones will not. He has had only one case of arsenical multiple neuritis caused by administration of the drug in large doses. That he thinks was not all his fault. He was giving arsenic at that time hypodermically in large doses, which he has since stopped. He went away on a vacation and the case, he thinks, was not watched as carefully as it should have been. He always watches the knee-jerks with extreme care, and if he sees any sign of their disappearance or weakening, he stops the drug at once, as this is a sign of beginning neuritis. It never occurred to him to treat a case of chorea by hypnotism.

Dr. Howell T. Pershing, Denver, stated that he believes in large doses of arsenic for chorea, but that he has long since ceased to use Fowler's solution. He now gives eacodylate of sodium in a 1 to 60 solution, which corresponds in arsenical strength to Fowler's solution. It can be given in doses up to 20 and even to 30 minims three times daily without causing any gastrointestinal disturbance. He has had no cases of arsenical neuritis since he began using it, five years ago. He stated that he has never recommended an operation in any case of that kind, though he has been present at and has consented to such operations.

\section{THE RADICAL OPERATION FOR EMPYEMA OF} THE ERONTAL SINUS.*

\section{W. FREUDENTHAL, M.D. NEW YORK CITY.}

The practice of rhinology some jears ago was in great danger of becoming monotonous. At our conventions the papers on reflex neuroses, adenoids and deviated septa were too numerous and were discussed over and over. What a pleasant change has taken place since, and how differently we treated "nasal catarrh" in the past from! what we do now! Each case of atrophic rhinitis and of ozena is a study in itself, and every disease of the accessory sinuses means good judgment and labor. But just this change has lent new interest to our work. Foremost in this respect are the affections of the frontal sinus.

In the paper which I have the honor of presenting to you, principally the chronic forms of suppurative frontal sinusitis are dealt with. In order not to be misunderstood in my conclusions, it will be wise to state from the start that by far the great majority of cases improve under intranasal treatment. And thus the patients are enabled to live for many years, now and then suffering little or more discomfort. In other patients the symptoms are somewhat more pronounced, but many would rather endure them than to undergo a serious operation.

* Read in the Section on Laryngology and Otology of the American Medical Association, at the Fifty-fith Annual Session. June, 1904. 
Before we decide on radical treatment by external operation we should exhaust all means possible to afford relief by intranasal procedures. It is an experience common to all of us that acute cases readily yield to a mild treatment, the exceptions only proving the rule. And I have nothing to add to this, excepting one case that occurred in the practice of a well-known colleague in a neighboring city.

Case 1.-On Feb. 20, 1893, I was called to see Mrs. - who had been treated a week for typhoid fever. She had fever ranging between 101 and $102 \mathrm{~F}$., and suffered greatly from a constant deep-seated pain over the right eye; constipation was also present. From the start she insisted on consulting a rhinologist, but the attending colleague objected on the ground that the frontal headache was due solely to the typhoid fever. Finally he was discharged, and his successor called me in. The pain was so pronounced that one could hardly touch the affected parts. The patient was unable to sit up in bed, and under the circumstances the examination was rather difficult.

Examination.-I found the spleen somewhat enlarged, no roseola and no pain over the abdomen. Anterior rhinoscopy revealed a highly congested and enlarged middle turbinal, between which and the septum, after cocainization, pus oozed out.

Treatment.-Removal of the anterior ethmoidal cells, followed by washing out of the frontal sinus; which was the seat of the acute empyema, brought great relief to the patient at once. Subsequent daily irrigations of the sinus and applications of silver nitrate removed all difficulties within five days, the patient being completely restored to health. The shortsightedness of the first attending physician is incomprehensible.

During and after an epidemic of influenza, we have all seen cases that yielded to mild treatment. I am fully convinced, however, that many a case failed to improve and puzzled the attending physician by simulating acute mania or the like. But we are not to discuss these today, and I shall now pass to the chronic forms of frontal sinusitis.

\section{CHRONIC FRONTAL SINUSITIS.}

Diagnosis.-The diagnosis of these cases is not always simple, and I wish we had some safe method by which we could always determine at the first examination whether or not an empyema of the frontal sinus exists. Of the different symptoms mentioned in textbooks, the tenderness over the sinus on slight or strong tapping or on pressure was absent in some of my most characteristic cases, while in others it was quite marked. Asthenopia was sometimes a prominent feature, and I agree with $\mathrm{H}$. Manning Fish that this sign comes more in evidence when the flow of pus from the sinus is temporarily checked.

Transillumination is mentioned here only on account of the peculiar behavior in one case. This was a gentleman with distinct empyema of the right frontal sinus, who was under my observation for nearly four years. The flow of pus continued day after day for years, the middle turbinal was absent, and one could easily reach with a probe far up into the sinus, which apparently extended a good distance above the eyebrow. Irrigation of the sinus was also very easy. Now, in applying the electric lamp for the purpose of transillumination, a large, bright area could be seen on the affected side, which was in strong contrast to the healthy side, which. appeared much darker-just the opposite to what was to be expected. The affected sinus was apparently much distended, and, since the flow of pus was no longer obstructed and the sinus emptied constantly, there was nothing to prevent the rays of light from penetrating the sinus walls and producing the translucency.

The most reliable evidence is afforded by probing and washing out the pus from the sinus. 'l'his is by far the safest way of reaching a diagnosis. The probing itself is difficult. Indeed, it is rarely possible to enter a sinus by passing a probe along the frontonasal duct, and I agree fully with Charles $H$. Knight when he says that "one is quite likely to get into the anterior, or frontoethmoidal cells, or even altogether fail to find the orifice of the canal." A perfectly thorough exploration of the sinus cavity can not be made with the probe. We are handicapped in many ways by the narrowness of the ficld in which we have to work, by copious hemorrhages, etc. Even on the cadaver it is impossible to do this or any operation completely through the nose. 'The reappearance of pus in the middle meatus after syringing the antrum of Highmore signifies that its origin lies higher.

Another important point arises now, as Hajek correctly says, viz., we have to decide whether the pus comes from the frontal sinus alone, from the anterior ethmoidal cells discharging into the infundibulum, or from both. It is sometimes extremely difficult to decide this, and mistakes in this direction are not infrequently made.

CHOICE OF METHODS OF TREATMENT.

Having reached a definite conclusion regarding the condition of the frontal sinus, what are we to do? Are we to treat our patients by intranasal methods, and how long are we justified in following up that course?

It is but natural that we should attempt to establish free drainage intranasally. If we succeed in that way by simply washing out the sinus, we run no risk in continuing this treatment for some time. But in most cases we have to remove the ethmoidal cells, and herein lies the great difficulty. The ethmoidal labyrinth, as Hajek correctly points out, can be freely opened through the nose, but not totally resected. The cribriform plate is dreaded, as a perforation of it will lead us directly into the cranial cavity.

Although, in a discussion on this topic before the Section on Laryngology of the New York Academy of Medicine, several colleagues reported that they had met with this accident and the patients nevertheless recovered perfectly, still it is at least unpleasant and does not bring the patient nearer to a cure. Still, we can give a good deal of relief to the patient by intranasal methods and are justified in continuing it-of course, with the consent of the patient-until threatening symptoms set in. But do not let us forget that such an empyema is in some instances a constant menace to the patient, and that other infections may arise from it. Permit me to quote the following case, which, though no positive proof of that theory, is nevertheless very suggestive:

CASE 2.-Mr. R. N., aged 45 years, had the grippe four years ago. Directly afterward he began to suffer from "nasal catarrh" and headache. Two years later he caught a cold and became hoarse, which condition lasted for several weeks. From that time on he occasionally suffered with sore throat. He came to me on account of hoarseness, which hindered him in business.

Examination.-On my first examination a dyspnea and a constant cough, with long inspiratory stridor, was noticed; little expectoration. In the larynx I found perichondritis of both arytenoids, which was the cause of the dyspnea. Examination of lungs and sputum, negative. In both nostrils there was marked atrophy of all structures; he removed masses of scabs by daily syringing. Probing and washing out of both frontal sinuses was done immediately, and at once he told me he had less difficulty in breathing. From that time on I frequently repeated irrigation of the sinus, and then the patient

1. Knight: Diseases of the Nose and Throat, p. 94. 
generally felt the same relief. But this was only a subjective sensation. Objectively, in the discharge from the frontal sinus, tubercle bacilli were detected at a time when the findings of the sputum were negative. Later on the sputum also showed tubercle bacilli, and finally physical signs of tuberculosis developed over the lungs. Although there is no direct proof of a communication between the affections of the frontal sinus and the larynx, it is only natural to associate both under the same etiology, as the possibility of a lymphogenetic infection of the latter from the sinus is very great. Therefore, 1 proposed to perform tracheotomy and immediately afterward do radical operation on both frontal sinuses. This seemed to me the only rational way of rendering a cure possible. The patient, however, lost two valuable months in delaying the operation and afterward disappeared.

Formerly a radical operation was considered necessary only when one of three symptoms was present, viz., brain pressure, swelling of the frontal region due to expansion of the frontal sinus, or dislocation of the eye, or all three. Since the genial Berlin surgeon, Dieffenbach, first performed that operation we have changed our views as to its indications. Nowadays, after treating the patient for several months and exhausting all kinds of intranasal treatment, it is our duty to propose an external operation under the following conditions :

1. When the purulent discharge is copious and the patient apparently loses ground.

2. When the discharge is fetid and combined with persistent headaches.

3. When the above-mentioned "classical" symptoms are present.

A combination of any of these symptoms naturally makes the indication so much more imperative.

After coming to a conclusion as to the necessity of an operation another difficulty arises, viz., which method is to be followed? Let me emphasize at once that there is no operation that will answer all purposes. Each case has to be treated individually, and each operation requires special rules.

\section{ANOMALIES IN THE SINUSES.}

The more I operate in this field, and the more sinuses I open in the cadaver, the more do I see that the variations in the size and shape of the frontal sinus are extreme. It is not very unusual to find the sinus entirely absent, or only rudimentary on one side and very large on the other. In 24 cadavers which I dissected I have found the sinus absent on one side three times. Repeatedly a cell was found between the two sinuses. In one case this cell extended quite a distance up on the left side, although there was no sinus at all. On the other side the sinus extended sharply from the median line all along the supraorbital margin.

A. Logan Turner, ${ }^{2}$ our esteemed guest from Fdinburgh, in his comparative studies found that the absence of one or both sinuses was not so very uncommon as may be thought; in other words, there was no cavity extending into the rertical portion of the frontal bone. "This, however, does not exclude the possibility of the existence of a small frontal air space between the two lamine of the orbital plate." Whether this air space is identical or similar to the above-mentioned cell which I found I can not decide, but it is probable. The difference in the size of the sinuses is sometimes very pronounced. More important, however, in case of operative intervention, is the difference in their height. In many cases the upper wall of the sinus does not even rcach the supraorbital margin. This I consider of such extreme importance for

2. A. Logan Turner: The Accessory Sinuses of the Nose, Edinhurgh. 1901 .
Killian's operation that we always should be on our guard against any such occurrences. Mistakes can often be avoided, but certainly not always. We shall speak about this later on.

\section{METHODS OF OPERATION.}

A colleague who has done good work along this line is Arthur Hartmann ${ }^{3}$ of Berlin. In his atlas he recommends an operation which is very much like the one we now frequently use.

One of the first to perform this operation radically and on a larger scale was Jansen. His incision along the eyebrow to the supraorbital notch is well known. The bony wall is opened just above the internal angular process of the frontal bone. At this point the bone is thinner than on the anterior surface and can be easily perforated. Then he removes the lower wall of the sinus, and in large cavities the edge of the anterior wall, and closes the external wound. There is no doubt that with this method the ethmoidal cells can easily be reached, but the exploration of the frontal sinus is not so easily accomplished.

In this respect the method of Riedel, who removes the anterior and $*$ orbital wall, offers greater advantages. but most authors agree that the cosmetic effect is a bad one. I omit here the description of the well-known methods of Ogston-Luc and Kuhnt, since they have been discussed frequently. Kuhnt's method is surely one of the best, but lesions of the infundibular cells of the labyrinth are not accessible. This is a great drawback, as the fontal sinus affections are almost invariably combined with diseases of the ethmoidal cells. According to Hajek's and my experience, the nasofrontal duct is so intimately connected with some of the ethmoidal cells that, in all probability, we can expect an affection of the latter when the frontal sinus is diseased.

Killian's Operation.-Killian of Freiburg, in order to reach all diseased parts, establish perfect drainage and make the cosmetic effect perfect, modified the former methods in vogue and claims excellent results for his own. As his procelure does not seem well known on this side of the Atlantic, you will permit me to give you a short résumé of it:

Killian's method is as follows: 1 . Start incision at the temporal end of the eyebrow, cutting directly through the latter to its median end; extend the incision in a graceful curve around to the side of the nose, and cut through the middle of the nasal process of the superior maxilla.

2. Incision of the periosteum about 5 to $6 \mathrm{~mm}$. above the supraorbital margin and parallel to it, followed by a second incision through the periosteum exactly in the center of the frontal process. His idea is to remove the anterior and the lower wall of the sinus with the preservation of a bony bridge, believing that this gives an excellent cosmetic appearance after the operation. In the line of the first periosteal incision he outlines the upper border of the osscous bridge he intends to preserve by light taps with the chisel.

3. Opening of the frontal sinus, either above or below the bridge and probing.

4. With chisel and hammer a furrow is made along the first periosteal incision, and principally with bone forceps the entire anterior wall is removed, followed, of course, by curetting of all diseased mucous membrane.

5 . The supraorbital margin is next outlined from the floor of the sinus, and the whole floor resected, thus leaving a part of the bone about 5 to $6 \mathrm{~mm}$. wide. 
6. Resection of the frontal process of the superior maxilla and the rest of the floor of the sinus.

\%. Resection of the anterior and middle ethmoidal cells and the respective parts of the middle turbinal.

8. Formation of a flap from the rest of the nasal mucosa, so that there remains a permanent and large opening into the sinus.

There is no doubt but that this operation is the most radical one, and that it apparently offers the best advantages for a permanent cure. But even this method will have to be modified to suit every variety of cases, if such a thing will ever be possible. For the present, I am not ready to recommend it for all cases; and, indeed, opinions differ widely as to the removal of the various parts.

While Riedel advocates the resection of the entire anterior and lower wall and Killian the same with the retention of a small bridge, Jaques leaves the vertical part of the bony wall intact, but removes the orbital part totally. Burchardt," a former assistant of B. Fränkel's, says: "It is contrary to general experience that cavities do not heal without partial removal of the orbital vault." I confess openly that so far as my experience goes, we can not as yet lay down such general rules.

In one case the whole anterior wall was affected and had to be removed in toto. On the other hand, in a case which had been operated on nine months previously by a general surgeon, all the symptoms had returned. On opening the sinus I found the lower wall intact but necrotic, and on removing it there was seen near the outer angle of the orbit a small pocket which was almost entirely partitioned off from the rest of the sinus. I have observed similar formations on the cadaver. It must be admitted that I could not have seen this pocket without following Killian's technic, and it is evident that in this case a cure could never have been effected without removing the lower wall.

Siebenmann of Basel praises Killian's operation as an advance in unilateral affections, but claims that his cosmetic results in double sinusitis were not good where the sinuses were very deep anteroposteriorly. We shall have to await his further communications before being able to judge of his proposed modifications.

Before opening the frontal cavity we are very often misled as to its dimensions. Even when we succeed in probing the sinus, we are mostly not able to judge of its height. We may believe that the sinus reaches upward above the eyebrow, and in trying to operate after Killian and open the sinus in this manner, we may get into the cranial cavity. Such a case has occurred in my own practice, and according to private information in that of others as well. It may be briefly mentioned here as an illustration and a warning to others:

CASE 3.-Miss - aged 45, born in England, consulted me on account of a constant purulent discharge from the nose and severe headaches.

Examination.-Both middle turbinated bodies had been removed, and it was easy to probe both frontal sinuses, as well as to wash them out. The flow of pus was very great. I recommended a double radical operation. As this had been proposed already by another colleague, she consented readily, being happy to be freed of her troubles.

Operation.-In the presence of several colleagues, I tried to follow Killian's method exactly. After marking the bony bridge, part of the bone above it was chiseled away, when to our surprise the dura mater presented itself.

4. Arch. ftir Laryngologie, vol. xv, p. 496.
The patient made a rapid recovery and left the hospital, the wound being entirely closed. I have not seen her since.

Now, what had happened here? We either had probed an ethmoidal cell, or there was some communication with the sinus of the other side, which was the sole cavity discharging the pus. Or we were misled in judging the distance which the probe had entered. I am inclined to believe the first mentioned.

The variations in the size of the sinus are so great that we should enter it only at the safest point, and that is not above the eyebrow. The most extreme variations I have found in my autopsies on 24 calavers I shall report here. The first one was in a male cadaver, apparently of Indian type. Here the left sinus that did not reach beyond the middle line was very much larger than the other. Its greatest height near the septum amounted to one inch, while on the other side it did not reach the supraorbital margin and was hardly half an inch in height. The second specimen (Fig. 1) is a characteristic type of another variety. The right sinus in this specimen is quite small, similar to the former case, while above it is a large cavity that belongs to the left sinus. You will observe I commenced Killian's operation on that sinus; the bridge has been prepared and

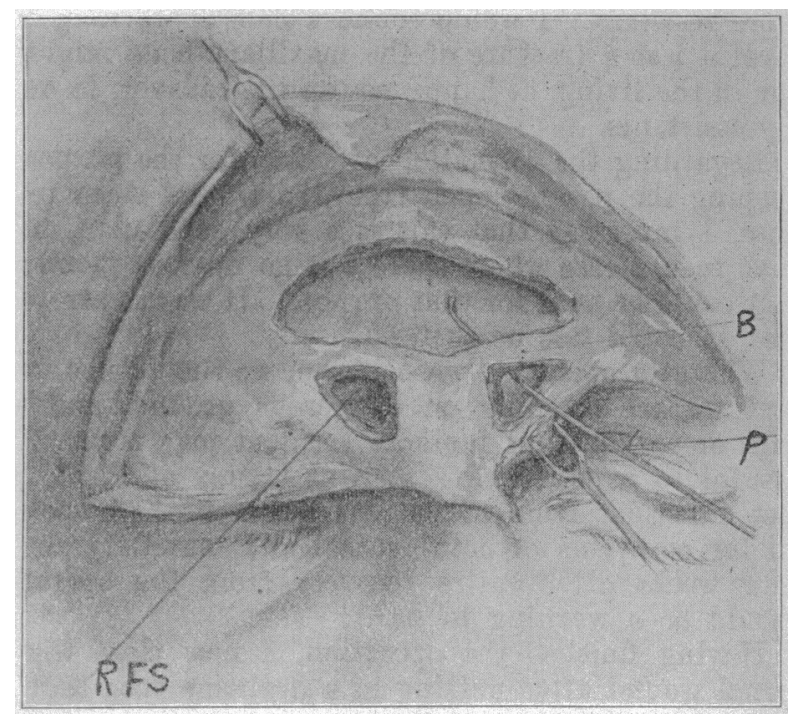

Fig. 1.-B, bridge between the two parts of left erontal sinus $P$, probe in left sinus; $\mathrm{RFS}$, right frontal sinus.

a probe is inserted from the smaller lower section of the sinus into the large upper one, which extends further toward the external canthus of the right eye than of the left.

Now, if we should have made an opening on the right side above the bridge, we would, in the first case, have entered the cranial cavity, and in the second we would have opened the sinus of the other side, neither of which was desired. At any rate, the above experience has taught me a lesson, viz., never to open the sinus first above the eyebrow. I always start the opening now near the upper inner canthus. Then I can probe the sinus readily and measure its dimensions. This is the only safe way to proceed. My experience on the cadaver has taught me the same, and I would advocate it here emphatically.

After opening the sinus as mentioned, I can easily probe my way and then prepare the bridge from above, if that be feasible. If the sinus ends upward at the 
eyebrow, we must naturally be satisfied to remove only the lower wall and then there can be no bridge. But when the sinus is large enough I believe in prescrving a bony bridge, thus improving greatly the cosmetic effect. It must be mentioned, however, that in some exceptional cases the bone is so affected that it is not advisable to leave any behind. In spite of this, the cosmetic effect is sometimes good, as in one case of mine in which the entire anterior wall had been removed and in which no perceptible depression was left. In another case of mine the bridge broke off during chiseling, but here, too, the result was so good that you can hardly say which side was the affected one. Still, we should not rely on such fortunate occurrences, and be on the safe side by leaving a bridge. The main thing in all these cases is to preserve the periosteum and let Nature do the rest.

If during the operation the horizontal incision alone does not give enough space, I do not hesitate for a moment to make another vertical incision after Kuhnt. This is, in men especially, of no importance, and makes the operation easier.

Regarding the removal of the frontal process of the maxillary bone, it is usually easier on the living than on the cadaver, where the bone is healthy and much more resistant. I would sound a note of warning to be careful lest a fracture of the maxillary bone might occur in the living, as happened, on the cadaver, to one of my assistants.

Regarding the formation of a flap for the purpose of keeping the passage open from the frontal sinus to the nose, I must say that this is a very good plan, but I have seen a case where there was no mucous membrane that could be used for that purpose. It was so atrophied that it could not be utilized.

Whatever operation we perform, we should not forget that we are treading on dangerous ground, and that with or without our fault an accident may occur. The case of so experienced a man as Castex of Paris, who lost a patient from meningitis whom he had operated on for empyema of both frontal and maxillary sinuses four weeks after entire recovery from the operation, should be a warning to us. ${ }^{5}$

Having finished the operation, I now close the external wound after putting in a drainage tube that can be removed at will. The primary healing of the wound is preferable, as healing by granulations often, or perhaps always, causes a depressed cicatrix, which is more or less conspicuous. The more we leave the external wound alone, the better will be the appearance afterward. And again, the more we plug the cavity from the outside and the longer we try to keep it open, the more marked will be the disfigurement.

Since the reactive secretion is practically nil, no tamponade of the cavity is necessary, and the wound generally heals per primam. Sometimes a slight retention of serous fluid causes a rise in temperature. This happened in the case of a young Greek. On the fourth day after the operation he felt pain on touching the wound near the inner canthus. His temperature had varied between 98.6 and 100 , when on the fourth day it rose to 104.6. The inner canthus was a little more swollen than on the previous day. On opening it simply with a probe, washing it out with a saline solution and keeping the wound open for a few days. the pationt quickly recovered. This place, i. e., the region of the inner canthus, seems to be a favored one

5. Intern. Centralbl. f. Lar., p. 166, 1904. for the retention of secretions, as abscesses will develop here also. 'These abscesses are sometimes of no importance, but usually a spontaneous respening of the wound will follow with the formation of a fistula. Such a fistula will seldom close, no matter what we try. It means, as a rule, a new operation, and indicates that the fir'st one was faulty in some way. I imagine we all have had such cases, and the wider our experience grows the less frequently will they be encountered. I am convinced that Killian's method is a step further in the direction toward an ideal operation, but it is surely not ideal yet.

And now, permit me to report the histories of some of the most significant of my cases, and I beg your indulgence for narrating first a case on which external operation had not been performed. It may be illustrative of a series of similar cases.

CASE 1.-Mr. J. K., aged 60, native of Austria, came to me on account of throat trouble on Nov. 2, 1899. On questioning him, he told me that for the last three years he had had a tickling in his throat, which had grown worse during the last month. He expectorated profusely and his appetite was failing. He had been operated on for nasal polypi about two years before.

Examination.-I found a postnasal catarrh and numerous polypi in both nostrils. The treatment was carried out accordingly, but the patient steadily grew worse. He had lost 25 pounds in weight, had no appetite at all, and slept very poorly.

Treatment.--As pus continued to flow in large quantities, the middle turbinal was removed, and then granulations from the anterior and middle ethmoidal cells curetted. I did this in the beginning quite often and also curetted the lateral cells with a curved ring-knife. The tissues were so friable and the adjacent orbital wall so thin that I always dreaded perforation of the latter. Afterward I was also able to scrape out granulations from the frontal sinus. Only after that was accomplished symptoms commenced to improve. The tissues broke down like paper, but there was no sign of any luetic infection. Although the patient was, and still is, suffering occasionally from dizziness, bad taste in the mouth and consequently loss of appetite, he has refused any radical operation up to the present time. When these symptoms show up I curette the nose and free him of all the accessible pus; then he goes to the country and feels better for some time, until the symptoms reappear. I have had him under observation for five years, and he feels grateful for the relief obtained thus far.

CASE 2.-Mr. E. A., aged 39, a musician, called on me first Feb. 4, 1898. He complained of a cold in his head which had lasted for several years. Fifteen years ago, while in South Africa, he had contracted lues, had afterward married, and his wife had given birth to a healthy child.

Examination.-His nose was clogged with a mass of foulsmelling scabs and crusts, after the removal of which a large perforation of the septum with ulcerations on its border could be seen. The left lower turbinal was atrophied, and on the anterior portion of the middle turbinal bare bone could be felt.

Treatment.-This was scraped away, and gradually the whole turbinated body removed. The antrum was washed out repeatedly, and always quite a mass of pus and debris brought away. But pus continued to flow from further up. After curetting away a mass of broken-down tissue I could finally pass a probe into the frontal sinus (June 14, 1898). There was no doubt that an empyema was also present here. It need hardly be mentioned that antisyphilitic treatment had been initiated the first time the patient had called.

The man led a rather irregular life, and disappeared for three months. On Sept. 18, 1898, he returned to me and said he had been playing in a country hotel and had used the potassium iodid sol. 100 drops t. i. d., but had given up the inunctions for obvious reasons. An edema had appeared over the left eye, and the patient felt some pain in that region. Other- 
wise he considered himself perfectly healthy. I must confess I was not very anxious to do a radical operation in this case, as I was doubtful about the outeome; and I trued my best to bring this process to a standstill by intranasal meutuods and by pushing the antiluetic treatment to its limit. It seemed as if we were to be successful. But our friend then absented himself again, and returned only when the pus had made an opening through the forehead. Without general narcosis, I enlarged this opening and found an exceptionally big cavity. it reached above the eyebrow surely one inch and extended out ward as far as the orbit. There were several sequestra, which were removed, and all the affected parts touched with nitrate of silver in substance. Drainage into the nose was then established and the wound dressed without suture. I am glat is say it healed very nicely within about three weeks and that the scars on the forehead are not very conspicuous now.

CASE 3.-Mr. C. M., aged 40, a wholesale merchant, consulted me, with quite acute symptoms. He told me he had been unable to breath well through his nose for the last three or four years. Whether there was pus present during all that time he did not know. Three months ago nasal polypi had been removed in several sittings by a colleague. After the last séance he had "dreadful" headaches. But Iater it seemed as if something had broken, and an abscess opened, and he then felt easier. About ten days ago this pain returned. It was so severe that he could not sleep at all. For the last two days he felt, on the contrary, like sleeping all the time, although the pain had not left him. He was somewhat dizzy, so that his wife had to lead him into my office, his mind did not seem to be perfectly clear, and he answered questions put to him rather slowly and hesitatingly. Temperature, $101 \mathrm{~F}$. No appetite.

Examination.-On examination $I$ found the parts over the right frontal sinus swollen, and the right eye somewhat closed. Great tenderness to touch at supraorbital margin. Transillumination showed shadow on the right side. In the nose there were several polypi and a mass of pus. Considering the seriousness of the symptoms, I advised an immediate radical operation, but the patient preferred to wait. This gave me an opportunity to remove the polypi. I was not able, however, to probe or syringe the frontal sinus, as the slightest toucb further up above the middle meatus caused a fainting spell. Nevertheless, the diagnosis was beyond doubt. He was growing weaker, felt like vomiting, etc., when, after eight days, his family consented to an operation.

Operation.-Oct. $4,1902,7$ a. m. Radical operation after Kuhnt. Eyebrows shaved, horizontal and vertical incision. Periosteum drawn upward and downward; sinus opened above the eyebrow. The cavity, which was filled with pus and granulations, was not very large. The entire anterior wall was affected, and consequently removed, and the rest of the eavity thoroughly scraped out. Drainage into the nose; Myle's tube inserted and sinus packed with gauze. Patient made an uneventful recovery and left the hospital on October 17. The wound was kept open for two weeks longer, when it was allowed to close, which it did within a few days.

Result.-Although the entire anterior wall was taken away. there is hardly any visible difference between the two sides, with the exception of a small retraction where the wound had been drained. I have seen more marked retractions in other cases, and find it best now to close up the external wound immediately following the operation.

One of the most interesting cases $I$ have seen is the following:

CASE 4.-Mr. O. W., aged 59, in the wholesale business, has a most peculiar anamnesis. He had been suffering for the last ten to fifteen years from headache on the left side. It used to "creep up and all over," and then was most severe under and behind the left eye.

History.-His digestion has always been poor, and grew worse two years ago after he had an attack of sunstroke. He became very nervous and sometimes felt like jumping out of the window. His family physician, a well-known and able col- league, took him to different nerve specialists of this city, who are recognized authorities. He went through different cures without experiencing the least relief. Finally he was advised to get away from business and take a trip to Europe. He went to Giessen, in Germany, to visit relatives, to whom he told his different ailments. He snuffied constantly at that time, and somebody advised him to consult a rhinologist. Dr. Reinewald of Giessen saw him and found pus in the middle meatus. He resected the anterior portion of the middle turbinated body and the anterior bulla cells, and advised him to see me atter his return to New York. For business reasons he had to remain for a while in Germany, and consulted another specialist, Dr. Warnecke, in Hanover. The latter found an empyema of the left antrum, which he opened with Krause's trocar from the lower meatus. He treated him for a week and again advised him to call on me immediately after his return to New York.

He consulted me first on Dee. 11, 1903, and on being questioned told me that he had had pain in the nose for years and also "catarrh."

Examination.-The opening made by Dr. Warnecke had closed and pus in the antrum was again found. The next day the antrum was opened from the alveolar process, whereupon a great deal of pus was washed out. This, however, according to $\mathrm{Mr}$. W., was not so putrid as that discharged after the first incision by Dr. Warnecke. The daily irrigations of the antrum met with some difficulties, the patient being a potator and of a very nervous temperament, which grew steadily worse. In spite of the irrigations, and every time after them, pus was noticed in the middle meatus. The cause of the disease, therefore, had to be looked for higher up. The removal of granulations and some ethmoidal cells could not be accomplished thoroughly, as the patient objected to it without general narcosis, but probing of the frontal sinus could be done after thorough cocainization. In transillumination the left sinus appeared darker than the other.

operation.-The diagnosis of chronic frontal sinusius was made and radical operation proposed. This was performed on Jan. 24, 1904. Both eyebrows were shaved and a horizontal incision made, reaching to the external margin of the eye. Then the periosteum was incised and pushed upward and downward. Very near the middle line, right above the eyebrow, the bony wall was opened with chisel and hammer. The whole anterior wall was found to be affected and removed in toto, mostly with bone forceps. The mucous membrane could be lifted up in pieces. The whole sinus was curetted and cleansed with hot sterile water. Then every part of it could be examined thoroughly. As the entrance to the nasal cavity was easily en larged with a ring knife, and apparently every diseased particle removed, I saw no reason for performing here Killian's operation, but inserted a Myles drainage tube and packed the external wound with iodoform gauze.

I have to mention again that the patient was an alcoholic, and consequently the free use of wine and whisky was per. mitted.

Hospital Record.-During the day he was greatly distressed with gas, but relieved by enema. Further on during his convalescence a rectal tube always made him feel easier. Temperature in the evening, 99 degrees; pulse, 60.

January 26,8 a. m., pulse, 68 ; temperature, 99 degrees; 9 p. m., pulse, 66; temperature, 100 degrees. Passed the day comfortably, but felt somewhat dizzy.

January 27, highest temperature, 99.6 degrees.

January 28 , wound dressed, after which he was very nervous for several hours, but comfortable later on.

January 29, 8 a. m., pulse, 60 ; temperature, 98.2 degrees. Complains of "cloudiness of vision." 7 p. m., pulse, 64 ; temperature, 99.6 degrees. Is slightly delirious; alcohol rub and plenty of whisky. During the following night nurse remarked, "Very vivid imagination."

January 30, wound dressed and looks healthy. No double vision. Patient rests easily.

January 31, complains of a disagreeable smell. Temperature 
normal. Patient gets out of bed for an hour. After that his recovery was uneventful. Granulations had to be removed on and off from the cavity, which closed up slowly.

Patient never noticed a smell again and felt like a new being. His residence being out of town, I kept him in the hospital until February 9. The external wound was almost closed and water injected into the rest of the cavity ran out through the nose.

Later History.-There is still some discharge from the nose, but the patient feels perfectly comfortable. Goes south for a few weeks and returns with the wound closed and feels well. The region of the frontal sinus feels to the touch like hard newly-formed bony tissue, and the only thing that shows a sign of the operation is a slight depression above the eyebrow.

The remarkable features in this case were the obscure symptoms during all the years of his sufferings, which did not lead any of his physicians to examine his nose. I believe the neurologist especially ought to learn the one lesson from this case, that in every instance of persistent headache not only the eyes, ears, etc., have to be examined, but also the nose. It is, perhaps, not amiss to believe that many a patient who died under "obscure brain" symptoms might have been saved by looking into the accessory sinuses.

Postscriptum.-May 30. Patient has always felt well and still feels well, but noticed a slight purulent discharge through the former wound. The probe enters not quite one-quarter of an inch and there is a little pus in the middle meatus. Whether we shall have to reopen and do another operation can not be said for the present.

CASE 5.- In this instance I did for the first time a typical Killian operation. The history is as follows:

History.-C. L., a young Greek, 20 years of age, was sent to me by Dr. A. Rose. His complaints mainly consisted in not being able to breathe through the nose. Besides, he expectorated occasionally thick pieces of phlegm from the back of his nose.

Examination.-On examination he presented the typical picture of ozena, both sides of the nose being clogged with the characteristic dried-in scabs, these also being present in the pharynx. Fe had noticed the bad odor himself, but did not like to talk about it.

Treatment.-After cleansing the parts it was seen that only the right side was affected, and the diagnosis of empyema of the right maxillary sinus and most likely of other sinuses as well was made. Consequently the antrum was opened through the alveolar process and a mass of putrid discharge was evacuated. Shortly, however, the water came out quite clear, but more pus was seen in the middle meatus and in the retropharynx. The next step was the cutting away of the anterior ethmoidal cells and some polypoid granulations, after which I could syringe the frontal sinus. With the probe I could also go up a good distance into the frontal sinus, apparently above the eyebrow. The odor still being present, and to a marked degree, and seeing no other way of getting rid of it, I proposed to make a Killian operation.

operation.-April 14, at 7:30 a. m., we began the operation, after giving him morphin, $1 / 4 \mathrm{gr}$. hypodermically, and putting atropin into the eye. Both eyebrows were shaved, as the hair afterward grows more symmetrically and it looks better. Horizontal incision, eurving around the inner canthus to the nose, preservation of the periosteum, outlining the osseous bridge, and chiseling an opening. through the anterior wall above it. The cavity was filled with granulations and cheesy masses, the curetting of all of which caused quite a profuse hemorrhage. Then the lower wall was opened and cut away, mostly with bone forceps. Although we did it carefully, part of the bridge broke off. But we left that as it was, only smoothing off the edges a little. After cleaning the whole lower part of the sinus, we removed the frontal process of the superior maxillary bone and curetted the ethmoidal cells. This stage of the operation took the longest time, as the bleeding in this strong young man as at this point more profuse than before. After stopping the flow of blood I could get into the sphenoidal sinus without difficulty and scrape it out. Finally the outer wound was closed by sutures, no packing put into the cavity and only a Myles rubber tube left to establish drainage between the frontal sinus and the nose. The operation lasied two hours, which was longer than usual. This ean only be accounted for by the severe bleeding. During the day the patient complained of a great deal of pain in the stomach, which was somewhat relieved after vomiting a good deal of blood. Did not pass urine and had to be catheterized repeatedly. The temperature during the next three days ranged between 99 and 100.4 and the pulse was accordingly.

Hospital Record.-April 17, 7 a. m., dressing changed for the first time. No reaction at the wound; slight edema of upper eyelid. No double vision. Stitches taken out and no more atropin used. Patient feels comfortable. Highest temperature, 99 degrees.

April 18, 8 a. m., temperature, 98.6 degrees; pulse, $70 ; 6$ p. m., temperature, 101 ; pulse, 96 . Complains of headache, but slept well.

April 19, 7 a. m., temperature, 99.6 degrees; pulse, 78. Dressing changed; wound looks well; tenderness and slight swelling near inner eanthus; 3 p. m., temperature, 104.6 ; pulse, 110. Dressings changed; tenderness more marked. As there was no other symptom to account for the sudden rise in temperature, the possibility of retention of pus or serum was brought to my mind. With the end of a probe the wound was opened and a few drops of a serous fluid escaped. The saline solution was injected and came out through the nose quite clear. Wound kept open. Patient slept restlessly and awoke at $3: 30 \mathrm{a} . \mathrm{m}$. in profuse perspiration.

April 20. During the night the temperature had gone down gradually so that at 8 a. m. it was 98.8 ; pulse, $80 ; 4$ p. m., temperature, 100.2 ; pulse, 80.

April 21 and 22, temperature normal.

April 23, pain in right eye; edema of eyelid gone; acute conjunctivitis, which brought up the temperature to $101 \mathrm{de}$ grees and once to 102 degrees. Instillations of sulphate of zinc removed the conjunctivitis entirely by April 26.

It must be mentioned here that the patient had been suffering for years from an eczema over the whole body. This appeared on the forehead and it seemed that in rubbing his eye he brought some of the eczematous secretion into the conjunctival sac, thus producing conjunctivitis.

From April 26, normal temperature. Patient discharged from sanatorium on April 27. April 29, rubber tube taken out and wound allowed to heal. There remained a small fistula for two weeks. After touching the borders with pure nitrate of silver this closed too.

Result.-The final result so far is excellent. Externally there is no disfigurement and only a very small scar visible. The discharge from the nose has not stopped entirely, but the patient feels no discomfort whatsoever. The remarkable features in this case were, firstly, that no disfigurement took place, although a part of the bridge had broken off. The periosteum, of course, had been kept intact and the newly formed tissue seems now as strong as that of the other side. Secondly. the sudden rise of temperature to 104.6 degrees $F$. on the fourth day was somewhat startling. There was nothing to account for it, excepting the retention of a small quantity of serous exudation. This is an unusual occurrence in our cases, but of no account, since the fever generally subsides after letting ont the fluid, just as it did in our case.

I want to remark that this was not a case of ozena. as I understand it, and as described by me at the Madrid Congress, but one of frontal and maxillary sinusitic with a bad odor.

CASE 6.-Miss B. S., aged 28, actress, had had influenza three years ago, after which a "catarrh" set in. A year later the right maxillary sinus had been opened by a dentist. There is now a great deal of purulent discharge from the nose, as well as a bad odor, that annoys her greatly. She also suffers very much from headache.

Examination.-On examination I found polypi in the nose 
and much pus. After removing the polypi the diagnosis of empyema of the antrum was made and radical operation proposed.

Operation.-This was performed on September 5, under general anesthesia. The bleeding was quite profuse and could only be stopped by pressure on the facial artery. This did away with the necessity of having to plug the antrum and wait for a day or two to complete the operation. The entire mucous membrane had to be removed, as it was necrotic. She experienced much relief after the operation, but pus continued to How. About six weeks later I removed the middle turbinal and also some small polypi and found the frontal sinus to be also affected. Bare bone could be felt and the tissues broke down easily on touching them with the ring knife. After trying this intranasal curetting for weeks and the headache still being very persistent, the radical operation was proposed and accepted.

Second Operation.-Dec. 6,1903 , at $2: 30 \mathrm{p} . \mathrm{m}$. She had received morphin, or. 1/6, hypodermically and atropin into the eye. Both eyebrows had been shaved previously. The horizontal incision was made and the bridge outlined after Killian's method. As I had decided to enter the sinus first always below the bridge, I did so here. I must say I am not sorry for it, as the sinus just reached as far upward as the supraorbital margin. I would have gotten into the cranial cavity had I tried to chisel first from above the bridge. The operation was performed in the same way as in Case 5, but, of course, there was no bridge preserved. The whole sinus, which was small, was scraped out, the nose entered and a drainage tube inserted. The septum interfrontale was intact. Wound closed entirely by sutures and dressed. By $3: 45$ p. m. the operation was over, i. e., after one hour and a quarter.

Hospital Record.-At midnight the temperature was 100.6 regrees; pulse, 108 . She was catheterized and vomited three times during the night. No sleep.

December 7, 8 a. m., temperature, 100.6; pulse, 108; voided 5 ounces of urine; 8 p. m., temperature, 99 ; pulse, 100 ; morph. sulph., 1/4. At midnight catheterized ( 6 ounces). Slept very little.

December 8 , temperature 99 degrees (mouth); pulse, $94 ; 4$ p. m., temperature 98.4 degrees; pulse, 94 ; voided urine; vomited at 5 .

December 9, temperature 99 degrees (mouth); pulse, 94; wound dressed; no reaction. After that the healing of the wound was uneventful, there being no fever and no unpleasant. symptoms.

Result.-On December 24 she left the hospital. I saw her at $m y$ office and I discharged her entirely cured six weeks later. There is now, a year later, so little to be seen externally that it is noticeable only on close inspection. There is no more discharge of pus. Indeed, this case healed in an ideal way.

In a further case I performed the typical Killian operation with preservation of the bridge, etc., but I shall await the result before publishing it in detail.

\section{cONCLUSIONS.}

In formulating conclusions, I would say:

1. Regarding the conservative treatment of these cases, the remarks made by $\mathrm{A}$. Kuttner ${ }^{6}$ of Berlin are much to the point. Everyone of us ought to try to live up to this conservatism as much as feasible.

2. In those cases in which we have to operate, Killian's method seems at present to give the best results.

3. The first opening into the frontal sinus must always be made below the outlined bridge, and only after exploring the sinus should another above it be made.

4. In the latter case we leave a bony bridge which helps toward improving the cosmetic effect.

5. Closing of the external wound immediately after

6. Berliner klin. Woch., p. 370, 1904. the operation is by far preferable for such cosmetic affect.

1003 Madison Avenue.

\section{DISCUSSION}

ON PAPERS OF DRS. FREUDENTHAL AND TURNER.*

Dr. George L. Richaros, Fall River, Mass.-I have had considerable experience with what is known as the Ogston-Luc operation and $\mathrm{I}$ published the results of a number of cases three or four years ago. Later experience has led me to the conclusion reached by Dr. Turner, that obliteration of the sinus must be brought about. One case which went along without symptoms for three years became reinfected and another operation was necessary. This time the sinus was obliterated. The question of the character of the operation can not be decided in advance of the time when the patient is on the table. As a rule, the question of deformity is not likely to be considered. But $I$ have noticed that although the patient says beforehand that it makes no difference as regards the deformity, he is likely to wonder if it could not have been done with less deformity. Paraftin might be used to advantage, but has not been tried long enough yet to determine.

As to the statistics of the Ogston-Luc operation, if these cases could be analyzed, would it not be found that in the cured cases the ethmoidal cells were not affected? A certain amount of time must be allowed to elapse before one can tell whether the case is cured or not. I have gone over Killian's thirteen published cases. ${ }^{1}$ Case 1 was six months under treatment, and he says that when discharged there was only a little pus in the nose. I do not think that can be called a cure. He makes the statement that there is no deformity except when you look closely. Case 2 was sixteen days under treatment. Case 3 was treated for two months, with some resultant deformity, but evidently not enough to prevent marriage. $\mathrm{He}$ says the deformity was due to the use of too strong carbolic acid. One point as to the degree of deformity should be remembered-what we would consider great deformity would be considered slight in Germany. Case 4 had been a year under treatment and still had double vision and double abscess. Case 5 was a double frontal, under treatment for one month, with pus still present in the nose. We must consider that in these early cases he may not have obliterated all the cells of the nose. Case 6 was treated for fourteen days, with good cosmetic effect. Case 7 was treated sixteen days, and the right frontal region was deeper than the left. Case 8 had recurrence and he found at the second operation that a small fistula leading into the other sinus had been overlooked at the first, showing that great care must be exercised, since it is so easy to make such mistakes. After nearly two years he operated on the other sinus and effected a cure after about a month and a half. Case 9 had double vision and was treated for five months. Case 10 was treated twelve days. Case 11 was treated three months and two days and had temporary double vision. Case 12, treated for two months and eleven days, was not yet healed. So I question whether any sinus trouble can be reported as absolutely healed until sufficient time has elapsed to be sure that recurrence will not take place.

The last word has not yet been spoken on the subject, nor the best method of operation absolutely determined. If we would publish a careful record of all our cases, noting the method of operation and when the case healed, then our statistics would be worth something. The first thing to do is to get an opening under the supraorbital plate at the inner angle of the eyes and explore the sinus; if it is small, then obliterate it; if large, go up and down and do a complete Killian operation and take off the nasal process. When Killian works he stands behind the patient in order to obviate injury to the superior oblique and to get the relation of the cells better.

Dr. R. C. Mrles, New York City-For the last fifteen years $I$ have been working along this line, but $I$ have not yet made a report of my cases, except individual ones. Cases should not be counted as cures unless we are sure there is no pus in the cells

*The paper of Dr. Turner appeared in The Jounsal, February 4.

1. Archives f. Laryngologie, vol, xili, No. 
from one to four years afterward. I have done nearly all the operations except the complete Killian, and my most brilliant results have been accomplished through an operation I have not heard mentioned to-day. That is the thorough removal of the anterior ethmoidal cells and part of the floor of the frontal sinus through the nose. I can show cases with the most obstinate history which have recovered and are well to-day. Killian speaks of his operation as a radical one. I do not see how it can be called that, when a large cavity is left which often contains pus. I have had difficulties with the eye in removing the floor far back beyond the optic nerve. We are liable to have abseess form which may destroy the sight. I think the secret of our success in many cases depends not so much on the amount of scraping and packing, as on securing a good, large opening from the nose into the frontal sinus. The anatomy is more favorable for this and where the ethmoidal cells are large and other conditions are favorable, if the parts can be broken down easily and the ethmoidal cells all removed, we will get our most satisfactory and brilliant results, whether we do the operation beneath the brow or above it. We may be able to educate people to consent to an operation, leaving such deformity as we have seen, and this $I$ am trying to do, injecting some of the cases with parafin.

As to the difficulty of diagnosis spoken of by Dr. Freudenthal, I have had but little difficulty in getting a small tube in. I wrote a paper on this point along in 1890 and have been doing this work almost daily. One can not do this in a healthy sinus, but usually it can be done in a diseased sinus, and that is where it is desirable. When water is injected and returns full of pus, the diagnosis is differentiated and then one can measure how far up the instrument goes. The morning pain, which goes away in the afternoon, is due to the frontal sinus being half full of pus. Gas forms, and when this gas forces the thickened muco-pus out and escapes itself the pain disappears. I have never had a death under treatment, though one man died who refused operation for a long time and afterward consented. After three or four days he suddenly became unconscious and died.

Dr. E. E. Foster, New Bedford, Mass.-Last fall and winter I saw twelve radical operations on the frontal sinus, done by Professor Killian and his assistant, Doscent van Eiken. The results were excellent. There was one death of an old woman who was practically moribund at the time of the operation. Dr. Freudenthal mentioned the fact that Professor Killian does not shave the eyebrow; Professor Killian's reasons for not doing so are that he has had a few cases where the hair did not return, leaving a very objectionable appearance and cases where the hair grew so long that it was also objectionable. He cleans the brow with soap, alcohol and corrosive sublimate. I did not see an infection of the wound from the hair. He is very careful to remove all cut-off hairs from the skin incision before he continues the incision through the periosteum. An important point regarding the cosmetic results is to make several short superficial cuts at right angles to the long incision, thus enabling the operator, at the end of the operation, to accurately appose the much stretched edges of the incision. Diplopia occurred in several cases, but it was of only short duration. Professor Killian uses a long, narrow strip of iodoform gauze for drainage. He doubles the strip, placing the double end in the temporal side of the frontal cavity; the cavity is loosely packed; the two ends are pushed through the opening made in the floor of the frontal sinus. One end is used for packing in the nose, while the other end is brought out through the nasal orifice. A V-shaped chisel is used in making the supraorbital bridge and the boundaries of the opening through the nasal process of the maxillary bone. It has been stated that a large depression remains after the operation. I did not see any objectionable depressions in Killian's cases. In those cases where the depression is noticeable paraffin is used with excellent results. Post nasal tampons are not used, but the meati on the side to be operated on are packed with long rolls of cotton. The tampon in the middle meatus is removed when the flap is made. The flap is the mucous membrane from the nasal surface of the frontal proc- ess of the maxillary bone. The external wound is closed with aluminum wire sutures, except when there has been a fistula or the tissues over the bone have been involved in the inflammatory process, then the wound is only partly closed with a drain. The cases referred to by Dr. Richards were the cases first reported by Killian. Since then he has improved his operation in several important points, and, of course, developed greater skill. The Killian radical operation is not an operation to be attempted by the average operator.

Dr. Emil MaYer, New York City-Does Dr. Turner follow the method of Jansen in using the electrotrephine? Jansen is very fond of using this in his frontal sinus and mastoid work, and it seemed to me the stress laid on avoiding raw surfaces of bone was important.

Dr. G. E. Seaman, Milwankee, Wis.-My colleague, Dr. Hitz, and myself have been doing work on these cases during the last year, and we had several cases which seemed to be favorable for the Killian operation. We first did the operation on the cadaver a number of times, and were very careful to avoid wounding the pulley of the superior oblique muscle, and succeeded in most instances. In one case operated on, where the frontal sinus was very large, the resulting deformity was considerable at first; this has improved. In that case there was disturbance of motility of the eyes which persisted for some time, but at the end of three months it had passed away. In discussing these cases with Dr. Sifton of Milwaukee he told me that he had operated on a frontal sinus case several years ago and had found the hemorrhage very troublesome. He put a temporary ligature on the common carotid. Does Dr. Turner consider this a recognized procedure? Is it ever necessary or justifiable in his experience?

Dr. C. R. HoLmes, Cincinnati-I fail to see how obliteration of the cavity can be done in a large per cent. of cases. In the last ten or twelve years I have dissected a great many heads, and $I$ have had a large number of specimens where the frontal sinus extends back over the orbit and some where it extended back almost to the optic foramen. In such cases I do not gee how a radical operation can ever be successfully performed if we have any regard at all for appearance. I think the disfigmement is a very important factor, especially in young women. Even some men are not willing to take the chances of a radical operation if thereby they are to be disfigured for life. The oculist finds evil results from this condition on the eye. I have seen quite a number of cases of diplopia result and while after a time this becomes less, it is because there is a readjustment of the muscle. This, however, means a constant strain on the eyes for the rest of life, due to the effort of both eyes to work together. These people often suffer greatly with headache and exhaustion.

Dr. Kaspar PISchel, San Francisco-Allow me to put on record a case of optic neuritis and paralytic divergent strabismus caused by a suppurative frontal sinus. In spite of an early successful operation atrophy of the optic nerve followed. In order to inform ourselves, before the operation, of the of the frontal sinus I would suggest taking a skiagram. That will assist in the selection of the method of operation. In Killian's operation the "sinu-nasal" canal might be covered with skin grafts to keep it well open. To prevent a depression of the skin above the eyebrow, part of the sinus might be filled with paraffin covered with absorbable Cargile membrane. The bone flap shown on the screen by Dr. Turner seems to give an ideal cosmetic result. The sinus might then be lined by skin grafts as we cover the bone trough in radical mastoid operations.

Dr. F. C. And, Plainfield, N. J.-During the past winter I have assisted Dr. Coakley in a number of operations on the frontal sinus, and his method of operating has not been mentioned in this discussion. He removes the anterior wall, without disturbing the floor of the sinus, and curettes the walls of the cavity with great care, under illumination, and then packs with iodoform gauze. He aims to obliterate the nasofrontal duct, and to allow the cavity to fill up by granulation. Sufficient time has not elapsed in these cases to make sure there will be no recurrences, but there is apparent recovery in 
all that I have examined, as is evidenced by the fact that the wounds have healed, and there is no pus in the nasal cavities. A case that I operated on early in March by this method has just healed, but it was a very large sinus.

Dr. W. FreudenthaI-Dr. Turner has brought up the osteoplastic operations, though he has not done any himself. In some cases I find it impossible to do this because of the brokendown tissue which must be removed. I remember one case where $I$ removed the whole anterior wall, and a new wall formed. I have not seen a case of diplopia. I use atropin before the operation. But these cases of diplopia go more to the ophthalmologist than to us. I must admit that Dr. Myles has had a larger experience than $I$ and he is able to do more with these cases than most of us. In many cases I could not reach the frontal sinus, and it is often impossible to measure the distance. Dr. Turner himself mentions having attempted to enter the right sinus and got into the left one instead. Dr. Foster's point was well taken. The disfigurement in my cases was very slight, probably due to the periosteum being preserved. The last word has not yet been spoken on these operations and we shall have to learn a great deal more. Yet if we can save a few of those cases like the one mentioned in my paper, who was contemplating suicide, we have done a great deal.

Dr. A. Logan Turner-Much more was omitted from the paper that might have been said. We are not yet at the bottom of this question; there is still much to learn, but some day we shall be in better position to deal with these cases. I have not been educated to Dr. Myles' view that we can treat these cases through the nose. As regards treatment by drain. age through the nose, I know that there are cases in which satisfactory results have been obtained, but if we consider the anatomic configuration of the sinus, $I$ do not see how we are to expect a cure by this method. There were many points of detail which I did not give fully for lack of time. One point about which $I$ wanted information was in regard to the formation of a flap of mucous membrane described by Killian. Others as well as myself have had difficulty in understanding this point. With regard to the osteoplastic operation, I introduced this procedure from Hajek's new edition. There seems to be something in the Killian method of operating which is approaching more nearly to the result desired, giving excellent curative results with the minimum of disfigurement. I have had no experience with the use of the electric trephine. We can obtain good, smooth edges by the careful use of the chisel. I have always found hemorrhage to be well controlled with peroxid of hydrogen. This stops it very rapidly, just as it does in mastoid work. I do not know whether the common carotid has ever been ligated in these cases or not.

Dr. Holmes said he felt difficulty in seeing how the sinus conld be obliterated. I have had no difficulty whatever in doing this, either on the living person or on the cadaver. It is astonishing to see how readily the soft tissues of the orbit rise up while you are removing the floor of the sinus and obliterate the orbital portion of the cavity. It is wise to remove all of the bony floor and not to leave any bone at the apex of the orbit. Further, what Dr. Holmes said about the future of these cases is important. I shall take occasion to find out whether my old cases have developed any eye strain. I did not refer to the method spoken of by $\mathrm{Dr}$. Ard, viz., preservation of the osseous floor. Dr. Coakley probably obliterates the orbital part of the sinus by gradually filling it up with granulations.

Prophylaxis in Surgery.-It has always been my idea, wrote Dr. I. Sexton of New Orleans, that if surgeons would spend more time in getting the patient in proper condition to stand the operation, in having everything in readiness, in having assistants trained in what they are expected to do, and also if the least possible time were consumed in performing the operation, and if all lectures and explanations were suspender until the operation is finished, much less of the first necessary poison, viz., the anesthetic, would be required, and we would have fewer cases in extremis to deal with after operations.

\section{PRESENT STATUS OF ANTITUBERCUI.OSIS} WORK IN THE UNITED STATES.

SUGGESTIONS FOR A MORE EFFECTUAL CO-OPERATION OF AUTHORITIES, PHILANTHROPISTS, PHYSICIANS AND LAYMEN.*

\section{S. A. KNOPF, M.D. \\ NEW YORK CITY.}

The kind interest with which my first report in 1897 and my second report in 1902 on the tuberculosis problem in the United States was received by the members of the Section on Hygiene and Sanitary Science and of the American profession at large encourages me again to give a bird's-eye view of what is being done in our country in the combat of the great white plague. Between my first and second reports five years had intervened; between my second and third only two years have elapsed. My reasons for reporting after this shorter interval are to be found in the unusual activity of sanitary authorities of the medical profession at large, and of the philanthropic societies and individuals engaged in antituberculosis work. Far greater progress has been made during the last two years than in the preceding five or ten.

There are now no less than forty-eight American and five Canadian associations for the prevention of tuberculosis, working under the names of societies, committees or commissions. The following is as complete a list as I have been able to collect myself up to this date ${ }^{2}$ and to Miss Lillian Brandt, the very efficient statistician of our tuberculosis committee in the New York Charity Organization Society, I am indebted for such statistical material as was at her disposal.

SOCIETIES AND COMMITTEES FOR THE PREVENTION OF TUBERCULOSIS, AND STATE COMMISSIONS.

$$
\text { CALIFORNIA. }
$$

Southern Callornia Antituberculosls League-F. M. Pottenger, M.D., president, 226 Bradbury Bldg., Los $\Delta$ ngeles, Cal.

Tuberculosis Committee of the Medical Society of the State of Californla-Dr. F. M. Pottenger, secretary, 226 Bradbury Bldg., Los Angeles, Cal.

COLORADO.

Evangelican Iutheran Sanitarium Association of Denver, Colo. Frederlek d'Amour, president; Dr. Henry G. Merz, secretary, 632 17th St., Denver.

Jewish Consumptives Rellef Society.-Dr. C. D. Spivak, secretary, 1421 Court Place, Denver, Colo.

CONNECTICUT.

New Haven County Antituberculosis Association-Dr. Francis Bacon, president, New Haven, Conn. DISTRICT OF COLUMBIA.

Committee on the Prevention of Consumption of the Associated Charites-Dr. Wm. C. Woodward, chairman, 811 G St., N. W., Washington, D. C.

geORGIA.

Georgla Medical Commission to Investigate the Extent of Tuberculosis in Georgia, and Means of Stamplng Out the Disease. Dr. Charles Hicks, chairman, Dublin, Ga. ILliNoIs.

Committee on the Prevention of Tuberculosis of the Fisiting Committee on the Prevention of 'Tuberculosis of the Visiting
Nurses' Association.-Dr. Alice Hamilton, 79 Dearborn St., Chlcago. Illinnis State Association for the Prerention of Tuberculosis.-
nr. Fdmund J. James, president; Dr. Arnold C. Klebs, secretary, Chicago.

Committe on Tuberculosis of the Illinois State Medical Society. Dr. J. W. Pettit. chairman, ottawa. Ill.

National Antituberculosis Association. Incorporated in Spring. Natinnal Antitubercilosis Association. Incorporated in Spring C. O. Hanford, Alderman Butterworth, W. R. McDonough, all of Chicago.

*The discussion on the papers of Drs. Knopf and Price. In the Section on Hzriene and Sanitary Science of the American Medical Association, at the Fifty-tifth Annual Session, June, 1904, will Assoclation, at the Fift the paner of Dr. Price.

1. Owing to the large number of papers read at Atlantlc City it was Impossible to have this report appear before. During the six months since the paper was read a number of new societies have been formed and several new institutions established. Through the courtesy of the editor of THF JodRNAL, the manuscript was returned to me in order that I might bring the statistical portion as nearly as possible up to date (January, 1905). 